\title{
EDUCAÇÃO PARA A PAZ NO CENÁRIO VIRTUAL
}

\author{
BEATRIZ DANTAS BRITO* \\ NÁDIA MARIA BÁDUE FREIRE**
}

\begin{abstract}
RESUMO
O presente artigo tem como objetivo geral contribuir para a convivência na escola, local onde permeiam ideias, valores, hábitos, culturas diferentes que geram conflitos. Com a vinda da tecnologia digital, os conflitos ganharam uma nova dimensão, ampliando a distância tanto entre os estudantes, quanto entre esses mesmos alunos e seu professor. A diferença entre as gerações também gera conflitos, mais especificamente nesta era digital. A questão norteadora do artigo é: como a Educação para a Paz pode contribuir no cenário virtual, tendo em vista os conflitos interpessoais e mesmo geracionais? Para responder a esta pergunta, são visitados autores como Piaget (1971 1971; 2003), Freire (2011; 2021), Prensky (2001), em uma abordagem qualitativa, que permite um breve estudo sobre quais características a educação para a paz deve apresentar para contribuir na minimização dos conflitos interpessoais e intergeracionais na escola
\end{abstract}

* É estudante do $2^{\circ}$. Ano de Pedagogia, junto à Faculdade de Educação, da Unicamp. Fez curso de Informática, no Instituto Federal, concluído em 2019. É professora de Robótica na rede municipal de Bragança Paulista. Email: beatrizdantasza@gmail.com

** É doutora em Psicologia, Desenvolvimento Humano e Educação, pelo Laboratório de Psicologia Genética, da Faculdade de Educação da Unicamp. É psicopedagoga, professora universitária. É coordenadora do Grupo de Estudos "Educação para a Paz e Tolerância" (GEEPAZ), que pertence ao LPG, FE - Unicamp, orientadora deste trabalho.

Email: freirenadia@gmail.com 
presencial e na virtual; como se apresentam os conflitos diante das tecnologias. Este artigo também propõe a importância da formação de professores, incluindo a perspectiva da tecnologia; e nas considerações finas, estão algumas propostas sobre como a Educação para a Paz pode contribuir para minimização dos conflitos no cenário virtual, situando que o professor, além dos conhecimentos técnicos, deve conhecer os conflitos, bem como suas origens e as formas positivas de lidar com eles: pelo diálogo, cooperação, discussão de práticas morais por meio dos conflitos do cotidiano e também de vídeos com dilemas relacionados à convivência e aos problemas gerados pela tecnologia.

Palavras-chave: Tecnologia digital, Educação para a Paz, Conflitos.

\begin{abstract}
The general objective of this article is to contribute to coexistence at school, a place where ideas, values, habits, and different cultures generate conflicts. With the upcoming of digital technology, conflicts gained a new dimension, as they have widened the distance both between students and between students and their teachers. Generation gap also generates conflicts, more specifically in this digital age. The guiding question of this article is: how can Peace Education contribute to the virtual scenario, considering interpersonal and generational conflicts? In order to answer this question, authors such as Piaget (1962; 1971; 2003), Freire (2011; 2021), Prensky (2001) have been studied in a qualitative approach, which allows a brief study on which characteristics of Peace Education must present so as to contribute to the mitigation of interpersonal and intergenerational conflicts in face-to-face and virtual schools as well; how the challenges come about in face of technologies. This article also proposes an importance of teacher education, including technological education; and in the final considerations, there are some proposals on how Peace Education can contribute to the minimization
\end{abstract}


of conflicts in the virtual scenario, stating that the teacher, in addition to technical knowledge, must know the conflicts, as well as their origins and the positive ways of dealing with them: bt means of dialogue, cooperation, discussion of moral practices through everyday conflicts and also videos with dilemmas related to coexistence and the problems generated by technology.

Key-words: digital technology, Peace Education, conflicts.

\section{INTRODUÇÃO}

Tendo em vista um cenário pandêmico, a tecnologia mostrou-se imprescindível para que as interações sociais permanecessem ativas. Com a educação não foi diferente: muitas escolas aderiram ao ambiente online de salas de aula e turmas inteiras passaram a caber em uma tela de computador. Considerando que a interação virtual não deixa de ser social, temos que onde há relações sociais, há também a necessidade do debate quanto à convivência e à paz, visto os conflitos que naturalmente emergem.

Com a experiência nas aulas de robótica, vemos que os estudantes possuem conhecimentos prévios de ferramentas tecnológicas conforme suas atualizações, tendo em vista a forte presença nas redes sociais, local onde informações como essa são disseminadas. Mesmo o conteúdo das aulas sendo tecnicamente formulado a partir de tecnologias digitais, através de softwares e de conceitos que a robótica exige, os materiais didáticos mostram-se incapazes de acompanhar um avanço tão rápido. Com isso, o atraso também ocorre no diálogo com relação à convivência e os conflitos inerentes, considerando tal cenário virtual.

Os conflitos apresentados nas salas de aula virtuais ou mesmo híbridas, apesar de terem características próprias, como o cyberbulliyng, sua essência permanece na medida em que podem prejudicar a convivência, o desenvolvimento dos alunos, sua autonomia, a cooperação, o espírito democrático, a construção da identidade, a capacidade de se colocar no lugar do outro, a capacidade de escuta, de diálogo - tão importantes para o de- 
senvolvimento das competências tanto cognitivas, quanto morais e afetivas - e necessárias para que nossos alunos e nós mesmos, professores, possamos dar conta de realizar nossos projetos de vida. Sabemos, no entanto, que tal prejuízo depende da forma como os conflitos são trabalhados, enfrentados.

Se havia conflitos interpessoais na escola, a eles foi acrescentado um outro tipo de conflito, que ocorre principalmente em ambientes virtuais, chamados de conflitos geracionais ou intergeracionais, ou seja, que ocorrem entre os alunos, em sua maioria nascidos após o ano 1998 (Geração Z), já inseridos no mundo digital e os professores, nascidos mais ou menos em 1980 (Geração Y), quando a realidade virtual já existia, porém em menor inserção na escola e no cotidiano.

A Base Nacional Comum Curricular (BNCC) apresenta 10 competências, sendo que a respeito da Educação para a Paz, a competência 9 elege a Empatia e a Cooperação:

Exercitar a empatia, o diálogo, a resolução de conflitos e a cooperação, fazendo-se respeitar e promovendo o respeito ao outro e aos direitos humanos, com acolhimento e valorização da diversidade de indivíduos e de grupos sociais, seus saberes, identidades, culturas e potencialidades, sem preconceitos de qualquer natureza. (BRASIL, BNCC, 2018)

$\mathrm{E}$ as competências 4 e 5 dirigem-se mais especificamente às metodologias, incluindo a tecnologia e reforça, na competência 5 , a necessidade de

Compreender, utilizar e criar tecnologias digitais de informação e comunicação de forma crítica, significativa, reflexiva e ética nas diversas práticas sociais (incluindo as escolares) para se comunicar, acessar e disseminar informações, produzir conhecimentos, resolver problemas e exercer protagonismo e autoria na vida pessoal e coletiva. (BRASIL, BNCC, 2018). 
Desta forma, há articulação possível entre tecnologia e Educação para a paz, na resolução de problemas e conflitos por meio do diálogo, da comunicação, do protagonismo, dentre outros. Como a Educação para a Paz pode contribuir no cenário virtual, tendo em vista os conflitos interpessoais e mesmo geracionais? Pois é diante deste cenário de busca de novas soluções e de expectativas a este problema - que o presente artigo se propõe a refletir.

Como existem vários significados para "paz", é importante esclarecer que o conceito aqui utilizado é aquele coerente com o construtivismo, no sentido de: qual sentido de "paz" contribui para o desenvolvimento das pessoas, de nossos alunos e de nós mesmos?

Desta forma, a primeira parte deste artigo aborda a Educação para a Paz no referencial construtivista que explica como se dá o desenvolvimento; a segunda parte trata das tecnologias e seus conflitos; a terceira propõe a importância da formação de professores, incluindo a perspectiva da tecnologia; e nas considerações finas, estão algumas propostas sobre como a Educação para a Paz pode contribuir para minimização dos conflitos no cenário virtual, a partir dos autores pesquisados, como Piaget (1962; 1971; 2003), Freire (2011), Prensky (2001).

\section{EDUCAÇÃO PARA A PAZ}

A Educação Paz refere-se, principalmente, à forma como os conflitos são solucionados, a partir de uma perspectiva de aprendizado. Diante disso, temos que

$\mathrm{Na}$ escola encontram-se crianças e jovens organizados em níveis que permitem a convivência e as trocas sociais entre pares, onde borbulham ideias, opiniões, gostos, necessidades diferentes e até mesmo opostas, gerando alguns conflitos e ampliando outros. A forma como os conflitos são trabalhados vai apontar se estão contribuindo para 
que aprendamos a viver juntos, ou não. Por isso, a escola é reconhecidamente o espaço privilegiado em que podem ser criadas oportunidades para a Educação para a Paz, para aprender a viver juntos, por meio da busca de estratégias e de referenciais a serem praticados (FREIRE, 2018, pág. 1).

A Educação para a paz é um tema necessário para a convivência, pois traz em seu cerne formas intencionais, organizadas, planejadas não apenas para a diminuição da violência, mas para engendrar atitudes de cooperação, de solidariedade, de tolerância, de generosidade que perpassam o mundo da justiça e das virtudes, da ética. Portanto, está inserido na psicologia moral, na ética. É um conhecimento a ser aprendido, divulgado e experienciado na escola e em outros ambientes, dada sua necessidade e importância à convivência, seja presencial ou virtual.

$\mathrm{Na}$ teoria piagetiana, o desenvolvimento é construído nas trocas entre os aspectos endógenos (que incluem suas tendências hereditárias e genéticas) e os exógenos (o meio social em que está inserido, sua cultura). Enfim, entre o homem e o meio em que ele vive e convive. Sob essa perspectiva, as virtudes como a paz, o autocontrole (tão necessário à autodisciplina) também são assim construídas: o homem nasce com as possibilidades de vir a ser virtuoso e vai atualizar tal capacidade de acordo com as solicitações do meio em que está inserido, das pessoas com as quais se relaciona (FREIRE et al., 2011).

Esta fundamentação teórica interfere na prática pedagógica, bem como certa falta de conhecimento sobre ela e sobre a importância de se conhecer os conceitos a serem trabalhados, pois eles estão na base de toda compreensão. Compreendemos paz, por exemplo, de acordo com nossos conhecimentos prévios e muitas vezes é preciso ressignificá-lo para que seja entendido de acordo com os objetivos do presente artigo.

Geralmente, PAZ vem carregada de sentido de ausência de guerra. Aqui é apresentado um sentido diferente, próximo da 
ideia de que "Educar para a paz é educar para o conflito" - trazida por Pedro Sáez (2006), em suas Dez Propostas para uma pedagogia da Paz. Esta é a proposta de Educação para a Paz, que provoca a busca de alternativas de trabalho para uma convivência harmoniosa, Como o conflito representa desequilíbrio entre sentimentos, valores e atitudes antagônicas, para o reequilíbrio, cada um deve buscar estratégias por meio de reflexões e tomadas de consciência sucessivas que contribuem para o geram desenvolvimento.

Segundo Freire (2011), a Paz é construída e não apenas aprendida verbalmente, decorando seus diversos conceitos. Tal construção ocorre quando ideias, sentimentos, atitudes entram em oposição e geram situações de conflito que aborrecem, magoam, prejudicam e, assim, "colocam em jogo" a Paz: como resolver? O que fazer? Diante de um conflito, seja entre pares ou intergeracionais, seja em classes presenciais ou virtuais, seja um caso de violência física, ou de dano à dignidade, a Educação para a Paz ensina que o conflito desequilibra nossos valores, nossa cultura, nossas verdades, nossos conhecimentos. Ainda segundo a mesma autora, a experiência de tentar resolver os conflitos pode ser positiva ou negativa. $\mathrm{Na}$ sua forma negativa, pode ser uma experiência carregada de vingança, ofensas, retaliações, humilhações. Em sua forma positiva, pode ensinar a buscar respostas pelo diálogo, negociação, argumentação, de modo a voltar ao convívio e à paz anterior, agora mais fortalecida. Para isso, segundo Freire (2021), os conflitos são colocados em jogo por meio de reflexões: em qual ponto este conflito ofendeu minha dignidade? De levantamento de hipóteses: Como posso resolvê-lo sem uso de violência? Quais alternativas eu tenho? De retroaçoes: o que fiz que pode ter provocado este conflito? De empatia: Como meu ofensor estaria se sentindo para agir como agiu? De escolhas: se eu optar por dialogar, como devo conversar com ele? De tomadas de decisão: como sou a favor da Educação para a Paz, resolvi que vou conversar, expressar meus sentimentos, 
perguntar sobre os dele, ouvi-lo, de modo que nossa conversa chegue a uma solução que seja boa para nós dois.

Por isso, acreditamos que os conflitos do cotidiano podem ser aliados na construção da Paz.

Em contrapartida, "Violência é a ação (ou ações) na qual a força e a intimidade são usadas para se obter alguma coisa." (PHILIP, 2008, p. 47). É obstáculo ao desenvolvimento na medida em que tem como objetivo impedir o pensamento, a reflexão, a argumentação - e requer a obediência cega. Por isso, a violência prejudica na tarefa de educar alguém.

\section{TECNOLOGIA E SEUS CONFLITOS}

Após as revoluções industriais, temos que a utilização do termo "tecnologia" vem sendo contemplada em diversas áreas do conhecimento, possibilitando divergentes interpretações quanto ao seu significado e distanciando-se da conceituação tradicional. Assim, faz-se necessário caracterizar a perspectiva da palavra tecnologia que aqui é empregada. Segundo Longo (1984, pág. 90), “tecnologia é o conjunto de conhecimentos científicos ou empíricos empregados na produção e comercialização de bens e serviços", tendo em vista o mercado comercial de desenvolvimento de produtos.

Partindo para uma abordagem mais intencional para nosso caso, em que se vê recursos tecnológicos como ferramentas contribuintes em processos pedagógicos, o intelectual brasileiro Álvaro Vieira Pinto afirma: "A função da tecnologia coincide com a promoção da liberdade pelas perspectivas que abre ao homem de refletir sobre si, seus problemas e exigências" (PINTO, 2005, pág. 79). Dessa forma, temos que a tecnologia abrange o termo liberdade diante do processo da Educação para a Paz, visto que com a tecnologia, o acesso à informação tornou-se mais democrático.

Em contraponto a isso, a tecnologia e o aproveitamento de recursos digitais estão intrinsecamente atrelados ao uso de telas. 
Em 2019, a OMS (Organização Mundial de Saúde) publicou um guia completo com recomendações sobre o uso de telas. A OMS afirmou que crianças até 4 anos devem passar no máximo uma hora por dia diante delas, visto que o excesso de exposição pode resultar em problemas no desenvolvimento social, cognitivo e físico da criança, como sedentarismo. "O início da infância é um período de rápido desenvolvimento e um tempo quando os padrões de estilo de vida familiar podem ser adaptados para aumentar os ganhos de saúde", afirma o diretor-geral da OMS, Tedros Adhanom Ghebreyesus. Além deste, a SBP (Sociedade Brasileira de Pediatria) também se posicionou em 2020, listando problemas que podem decorrer ao longo da exposição excessiva a telas, tais como: transtornos de sono, cyberbullying, problemas auditivos, transtornos posturais, hiperatividade, entre outros. No mesmo ano, a nova atualização da Classificação Estatística Internacional de Doenças e Problemas Relacionados à Saúde (CID 11) definiu o uso abusivo de jogos eletrônicos como doença.

Partindo agora da perspectiva pedagógica, sabemos que o desenvolvimento da criança acontece através do lúdico, ela precisa brincar para crescer (PIAGET, 1971). Ainda segundo Piaget (2003), vemos que crianças de dois a quatro anos não possuem conceitos formados, e sim pré-conceitos, adquiridos através de experiências. Dessa forma, a criança já elabora pensamentos e informações a respeito do mundo, mas ainda não possui o desenvolvimento cognitivo completo para a formulação do próprio conceito (PIAGET, 2003) 2003). Já na primeira infância, temos que a linguagem e a representação mental começam a fazer parte da vida da criança com mais intencionalidade e intensidade, ou seja, a criança compreende melhor sua realidade e tende a copiar o que está vivenciando (FREIRE, 1997). A questão a ser refletida é até que ponto ferramentas digitais podem contribuir ou atrapalhar o desenvolvimento da criança como um todo, visto que, como ressalta Paulo Freire: "não é a educação que forma a sociedade de uma determinada maneira, senão que esta, tendo-se 
formado a si mesma de uma certa forma, estabelece a educação que está de acordo com os valores que guiam essa sociedade" (1975, p. 30, tradução nossa).

Diante da escola, sabemos que o ambiente virtual não possibilita uma experiência completa de convivência e, de acordo com Freire (1997, pág. 45): “De que nada vale esse enorme esforço para alfabetização se a aprendizagem não foi significativa. E o significado, nessa primeira fase de vida depende, mais do que qualquer outra, da ação corporal". Além disso, Kishimoto (2010) afirma que, ao brincar, a criança vai garantir a integração social além de exercitar seu equilíbrio emocional e atividade intelectual. Diante do ambiente virtual, temos que a integração social é pouca ou nenhuma, visto que as telas delimitam fisicamente tal prática.

\section{1 Conflitos intergeracionais}

No que diz respeito à Educação para a Paz como promotora de desenvolvimento, por mais que os termos "conflitos geracionais" tenham tido ascensão nos tempos atuais, a verdade é que há décadas são discutidos, visto sua importância. A psicóloga alemã Jane Loevinger (1959) já definia tais conflitos geracionais como consequentes da resistência natural dos filhos ao processo de socialização imposto pelos pais, visto as mudanças e evoluções sociais de cada cenário histórico-social.

Tais mudanças sociais resultam em rompimentos e divergências no sistema social como um todo, incluindo-se a escola, consequentemente pressionando a substituição dos antigos padrões de comportamento pelos novos. No entanto, Moragas (1997) conclui que as relações intergeracionais podem ser solidárias, visto que são capazes de complementar-se em diversas e específicas situações. Ainda segundo o autor, quando se admite a necessidade da compreensão entre gerações e os jovens são educados para tal conduta, a integração é incentivada entre as diferentes idades e consequentemente reduz-se o conflito social, coerentemente com a Educação para a Paz. 
Contudo, mesmo que o estudante seja educado quanto à compreensão das questões geracionais, é preciso que o educador também esteja ciente do imutável processo de substituição de comportamentos, visto que os conflitos em salas de aula emergem, em grande parte das vezes, de tais situações, são os conflitos intergeracionais.

As novas gerações estão imersas em um contexto tecnológico. O professor Francisco Rüdiger (2011, p. 13) conclama os colegas de profissão: "sim, somos nós a origem da era da informação, os criadores da cybercultura”. Entendendo-se aqui cybercultura como sendo a cultura no ambiente digital, temos que diante disso, professores e alunos precisam interagir em cooperação, unidos para alicerçar um novo padrão de conduta on-line que se instalará e se renovará frequentemente.

Os professores como sendo mediadores das relações sociais dos alunos em salas de aula, muitas das vezes são o que o educador inglês Marc Prensky (2001) intitula como "Imigrantes Digitais", em oposição aos "Nativos Digitais". Os nativos digitais apresentam comportamentos de quem já nasceu totalmente imerso em uma era tecnológica e "falam" a linguagem digital desde que nasceram. Os professores, chamados de Imigrantes digitais, são aqueles que não nasceram em uma era digital, e por necessidade migram para esta nova realidade.

Os conflitos intergeracionais podem tardar o objetivo do desenvolvimento da Educação para a Paz, há uma "geração digital" (TAPSCOTT, 1999) transicionando da tela da televisão para as telas dos smartphones, cujas disposições exigem das escolas investimentos na docência.

Prensky (2001) destaca que os jovens da geração X (nascidos entre 1960 e 1980) e Y (nascidos entre 1980 e 1990) nasceram em uma era totalmente diferente da geração $Z$ (a partir de 1990, os nativos digitais), possuindo divergentes maneiras de pensar, agir e comunicar. $\mathrm{O}$ acesso à informação nunca foi tão fácil como é hoje, na palma de nossas mãos. 
Tapscott (1999) defende que uma das maiores peculiaridades desses conflitos geracionais é que a geração $Z$ está a crescer cercada pela mídia digital, e pela primeira vez, na história da humanidade, as crianças são mais informadas e qualificados que seus pais e professores em uma inovação tão importante para a sociedade: a tecnologia. Os professores estão sendo diariamente desafiados a atualizarem seus conhecimentos, entendendo que estão diante de uma geração que conhece e domina mais a tecnologia do que eles e que interagem com o conhecimento e com a informação de formas diferentes.

A sociedade vem evoluindo e o modelo de uma educação do século XIX, fundamentado na Revolução Industrial, torna-se questionável diante dos recursos tecnológicos dos estudantes de hoje e do contexto no qual estão inseridos. Para o educador inglês Marc Prensky (2001), esses jovens e crianças estão acostumados a obter informações de forma rápida e dinâmica, recorrendo primeiramente a fontes digitais e tecnológicas antes de procurarem em livros ou na mídia impressa.

Os conflitos entre nativos digitais e imigrantes digitais estão no fato de que, segundo o autor, os nativos digitais estão acostumados a interagir com diversas mídias ao mesmo tempo, em função de sua convivência diária com telas praticamente desde que nasceram. Além disso, possuem o hábito de ficarem constantemente conectados com amigos e colegas, principalmente através do uso de redes sociais como Facebook, Whatsapp, Instagram, Twitter, entre outros. Essa geração, como Prensky (2001, pág. 24), afirma: "pensa e processa informações de forma diferente" e sua familiaridade com a linguagem digital faz com que ela seja para eles como uma segunda língua.

Em contrapartida, grande parte dos professores, chamados por Prensky como imigrantes digitais, ofertam aos alunos situações de aprendizagem bem diferentes e até opostas daquelas que eles esperam. Para El Badouy (2018), os professores controlam os conteúdos e a tecnologia é um recurso eventual; a oferta de 
informações é controlada, lenta, com fontes limitadas; as tarefas são controladas e sequenciais; oferecem texto em vez de imagens, sons e vídeo; a informação é de forma individual; adiam a gratificação (nota) para o final do período; ensinam o que está no currículo, com testes padronizados.

\section{QUAL O PAPEL DO PROFESSOR DIANTE DOS CONFLITOS?}

Mesmo diante de dinâmicas inovações tecnológicas, o professor não deve considerar-se incapaz de compreender os avanços do mundo digital ou amedrontado diante da criação de novas inteligências artificiais.

$\mathrm{Na}$ perspectiva construtivista, segundo Freire (2011), os conflitos podem ser oportunidade de desenvolvimento cognitivo, na medida em que mobilizam para busca de estratégias que ajudem a resolvê-los. De desenvolvimento afetivo, quando desperta o desejo de resolver o conflito e de desenvolvimento moral, quando as estratégias são utilizadas de forma justa para todos.

Partindo desse ponto, temos que a autoridade do professor pode passar a ser questionada em sala de aula se o mesmo mostrar-se como acanhado diante das inovações digitais e não buscar estratégias para superar tal estranheza. De maneira prática, é sobre a utilização de falas limitadoras como: "Essa tecnologia não é para mim!", "Na minha época não tinha isso", "Não sei mexer nessas ferramentas, são digitais demais para mim!", entre outras. Em certa instância, comportamentos como esses aumentam ainda mais a distância geracional entre professor e aluno, potencializando os conflitos.

Quando falamos em atritos geracionais entre educando e educador, cabe aqui o importante debate quanto à Educação para a Paz, segundo a qual a violência deve ser evitada, e as reações mediante os conflitos não podem refletir intolerância. Segundo Freire (2011), as reações de intolerância são as que apelam para violência física, verbal ou psicológica, como bater, insultar, 
constranger, radicalizar, dominar, coagir. Tendo em vista os conflitos interpessoais ou intergeracionais em sala de aula, o ato do professor, por exemplo, tomar o celular do aluno, em última instância, pode ser entendido como uma reação de intolerância, na medida em que impõe uma regra sem dialogar, sem discutir com o aluno sobre quais valores, quais princípios estão sendo quebrados ao utilizar o celular durante a aula.

O uso de celulares em salas de aula vem sido discutido desde antes da era dos smartphones, em 2007, com a ascensão dos telefones móveis. O Projeto de Lei 2.547/2007 foi proposto visando vedar o uso sem fins educacionais, de aparelhos eletrônicos portáteis em salas de aula, ou quaisquer outros ambientes de atividades educacionais nos níveis de ensino fundamental, médio e superior nas escolas públicas do País. Tal projeto de Lei não chegou a ser aprovado e até hoje não existe uma legislação geral, visto que cada escola estabelece suas próprias regras. Essa foi a primeira reação dos educadores diante das novas tecnologias: a proibição.

Por mais que um estudante possa permanecer com o microfone e a câmera desligados, há problemas e conflitos interpessoais diante da turma que não devem ser silenciados.

De fato, a pandemia somente potencializou um processo que há muito tempo já era adiado: a digitalização de práticas educativas. Isso inclui dinâmicas pedagógicas como atividades avaliativas, mas também - e principalmente - inclui questões sociais tais como os conflitos entre pares e intergeracionais.

O uso intencional de ferramentas tecnológicas na sala de aula é com certeza uma ótima estratégia para o professor. Uma dinâmica pedagógica é o uso de recursos audiovisuais como filmes e documentários, com o intuito de propor reflexões morais aos estudantes.

Segundo D'Aurea-Tardeli, os trabalhos com

[...] filmes tratam de percursos de vida e de conflitos; trazem personagens que criam uma identificação única com 
os espectadores, além de apresentarem tramas dilemáticas. Nesse sentido, os filmes são infalíveis porque são carregados de valores e constituem possibilidades de práticas morais com uma ação educativa implícita: algo nas narrativas merece ser ensinado e aprendido. (D'AUREA-TARDELI, 2018, pág. 14)

Além dos filmes e vídeos que podem ensejar discussões com os alunos para o trabalho com as práticas morais, há ainda documentários que contribuem para a conscientização quanto ao uso de redes sociais, como o documentário original Netflix "O dilema das Redes" (2020), que aborda importantes questões quanto ao tema, trazendo uma perspectiva de quem está por trás das redes sociais, desenvolvendo plataformas e ferramentas de softwares pensadas para manipular o usuário. Discutir sobre temas que envolvem tecnologia associados à convivência, à paz nas relações é criar oportunidade, na escola, para o desenvolvimento intelectual e moral tanto dos alunos quanto dos professores.

\section{CONSIDERAÇÕES FINAIS}

A internet muitas das vezes é território inexplorado por professores, tendo em vista os conflitos intergeracionais nesse artigo explorados. Contudo, de modo algum, tais diferenças geracionais devem amedrontar ou despertar um senso imediato de dominação no educador. Até porque, comportamentos autoritários e individualistas não condizem com o que aqui foi discutido quanto à Educação para Paz.

Como vimos, Paulo Freire afirma que não devemos tentar dominar a tecnologia, mas compreendê-la para que possamos então usá-la como instrumento do pensar e agir coletivo. Por aqui entende-se que as ferramentas digitais e tecnológicas não só podem, como devem ser utilizadas perante as salas de aulas, considerando a vasta possibilidade de aproveitamento. 
Ainda sobre o pensamento do autor, tendo em vista a denominação Paz e estando ela associada diretamente ao pensar e agir coletivo, uma Educação para a Paz é possível em um âmbito digital somente por via da compreensão do mesmo e dos conflitos decorrentes. Entenda-se aqui compreensão como não ligada à dominação.

Em vias práticas, isto é: o professor reconhece que o cenário virtual pode ser a ele desconhecido, mas, ao mesmo tempo, compreende sua importância diante das necessidades do atual contexto educacional. Logo, humildemente entende a necessidade de não somente buscar capacitações extras, mas também de aprender com os próprios educandos conhecimentos técnicos acerca das tecnologias. Serão professores e alunos interagindo em cooperação, unidos para alicerçar um novo padrão de conduta on-line que se instalará, se renovará e produzirá desenvolvimento a todos os envolvidos.

Desta forma, retoma-se a questão inicial: Como a Educação para a Paz pode contribuir no cenário virtual, tendo em vista os conflitos interpessoais e mesmo geracionais?

É importante lembrar que, mesmo com o entendimento técnico das ferramentas digitais, é preciso atenção às questões morais, à Educação para a Paz. Diante da internet, temos inúmeros termos e condutas que dificultam a execução de práticas para a paz, tais como a cultura do cancelamento, que expõe pessoas ao extremo, com o intuito de fazer com que sejam publicamente prejudicadas. Isto é, na prática, os estudantes difamam professores e até mesmo seus próprios colegas através das redes sociais. Um professor que retira o celular de um aluno perante a sala de aula, por exemplo, pode ser facilmente cancelado pelo mesmo e por seus colegas no Twitter. Além do mais, tendo em vista a criticidade dos estudantes, um professor que falha diante do processo de ensino, seja por excesso de autoridade ou falta na didática também pode ser facilmente cancelado nas redes sociais por seus educandos. 
Os combinados estabelecidos entre professor e aluno devem estar baseados em princípios morais e devem ser respeitados pelos dois lados, de forma que sejam entendidos, que tenham significado e por isso, sejam valorizados.

Ocorre que casos em que os combinados são impostos, se há descumprimento por parte do estudante, o professor toma iniciativas institucionais envolvendo a escola como um todo, sem diálogo, sem reflexões. Quando se tal descumprimento acontece por parte do professor, o estudante pode usufruir de sua liberdade de expressão, e ainda do anonimato, para expor o profissional da educação através das redes sociais.

Outro importante fator a ser relevado é quanto ao uso excessivo de telas, já pensando em possíveis maléficas consequências para o mesmo. Os estudos da OMS citados nesse artigo nos mostram o quão prejudiciais as telas podem ser. Portanto, mesmo que o professor compreenda a importância do uso das tecnologias digitais em sala de aula, mas ao mesmo tempo não saiba sobre tais questões, pode indiretamente prejudicar a saúde física e cognitiva dos estudantes através de práticas abusivas e não intencionais, ainda porque o uso de telas tem sido um assunto recorrente discutido entre os pais, logo, um professor sem tal conhecimento pode desencadear mais conflitos com os mesmos. Daí a importância da formação de professores para este novo cenário que a tecnologia digital apresenta.

A Educação para Paz no cenário virtual aqui discutida faz-se como indispensável, tendo em vista as atuais necessidades da presente realidade educacional. Entende-se aqui como não apenas papel do educador buscar conhecimentos, estudos e capacitações quanto às inovações tecnológicas a fim de saber lidar com os conflitos emergentes, mas também como função básica da escola providenciar opções de capacitação ao professor.

Estas reflexões podem inspirar propostas sobre como a Educação para a Paz pode contribuir para minimização dos conflitos no cenário virtual, de acordo com cada realidade escolar. 
A escola deve buscar atualizações. Somente um laboratório de informática, não basta. É preciso mais do que isso! É preciso consciência e intencionalidade quanto ao uso de tecnologias, além de conhecimento e participação nas redes sociais frequentemente usadas pelos estudantes. Atualmente, por exemplo, o órgão responsável pelo ENEM, o INEP, entendeu tal necessidade e busca comunicar informações sobre a prova através do perfil oficial do órgão no Instagram. Tais atitudes fomentam o interesse dos jovens e consequentemente fazem com que a comunicação entre as gerações seja mais clara e efetiva.

Atitudes como esta, formação de professores em tecnologia digital e em Educação para a paz criam oportunidades para uma convivência harmoniosa, onde os conflitos continuarão a existir, claro, porém com possibilidades de resolução positiva, pelo diálogo, cooperação e consequente desenvolvimento intelectual, afetivo e moral.

\section{REFERÊNCIAS}

BRASIL. Ministério da educação e do Desporto. Base Nacional Curricular Comum. 2018. Dispon;ivel em: http://basenacionalcomum.mec.gov.br/a-base Acesso em 20 de novembro de 2021.

D'AUREA-TARDELI, Denise. Oito filmes, oito livros. Americana: Adonis, 2018.

EL BADOUY, Eliane. Entendendo a geração de nativos digitais. In: DEFILIPPI, C; EL BADOUY E.; RASQUILHA L. VERAS, M. Inovação em sala de aula. São Paulo: Unitá Editora, 2018.

FREIRE, J.B. Educação do corpo inteiro: teoria e prática da Educação Física. São Paulo: Scipione, 1997.

FREIRE, Nádia M. Bádue Freire et al. Pilar da Educação para a Paz. Minicurso. Seminário Internacional da Educação do Século XXI. Unicamp, 2018. Não publicado.

FREIRE, Nádia M. BÁDUE et al (Org.). Educação para a Paz e a tolerância: fundamentos teóricos e prática educacional. Campoinas: Mercado de Letras, 2011. 
FREIRE, Nádia M. Bádue (Org.). Fundamentos teóricos e conceitos. Curso online: Educação para a Paz: ações formativas e estratégicas. Extecamp, Unicamp, 2021. Não publicado.

FREIRE, Paulo; ILLICH, I. Diálogo. In: Seminario Invitación a conscientizar y desescolorizar: conversación permanente. Genebra: Atas, 1974. Buenos Aires: Búsqueda Celadec, 1975.

KISHIMOTO, M. T. Brinquedo, brincadeira e a educação. São Paulo: Cortez, 2010.

LOEVINGER, J. Patterns of parenthood as theories os learning. The Journal of Abnormal and social Psychology. Disponível em: https://doi. org $/ 10.1037 / \mathrm{h} 048470$. Acesso em: 20 nov. 2001.

LONGO, W.P. Tecnologia e soberania nacional. São Paulo: Ed. Nobel, 1984.

MORAGAS, R. Gerontologia Social. São Paulo: Paulinas, 1997.

ORGANIZAÇÃO MUNDIAL DA SAÚDE. Notícia. Agência Brasil, 2019. Disponível em: https://agenciabrasil.ebc.com.br/saude/noticia/2019-04/oms-criancas-devem-ter-tempo-em-frente-telas-limitado-1-hora

PHILIP, Rita R. O respeito à igualdade. Trad. de Cecília Pompêo. São Paulo: Ciranda Cultural Editora e Distribuidora, 2008.

PIAGET, J. A formação do símbolo na criança. Imitação, jogo, sonho, imagem e representação de jogo. Tradução:Álvaro Cabral e Christiano Monteiro Oiticica. São Paulo: Zahar, 1971.

PIAGET, J. A construção do real na criança. Tradução: Paulo Bezerra. São Paulo: Editora Ática, 2003.

PINTO, A. V. O conceito de tecnologia. Rio de Janeiro: Contraponto, 2005.

PRENSKY, M. Digital Natives Digital Immigrants. In: PRENSKY, Marc. On the Horizon. University Press, v. 9, n. 5, out. 2001. Disponível em < $\underline{\text { http:// }}$ www.marcprensky.com/writing >. Acesso em: 01 nov. 2021.

RÜDIGER, Francisco. As teorias da comunicação. 1. ed. Porto Alegre: Penso.; 2011.

SÁEZ, Pedro. 10 propostas para a educação para a paz. Revista Pátio, Porto Alegre, n.38. p. 11-13, maio/jun. 2006.

TAPSCOT'T, D. Geração Digital: a crescente e irredutível ascensão da geração net. São Paulo: Makron Books, 1999. 